\title{
LAS CAMPANAS DE GÉNOVA
}

\author{
Bells of Genoa
}

Paolo D'Iorio

CNRS/ENS - París

RESUMEN: Este texto explora los diferentes aspectos que conforman aquella experiencia intelectual que sobrevino a Nietzsche al escuchar el sonido de las campanas de Génova. En un primer momento, considerará los tres niveles semánticos de esta iluminación: biográfico, literario y filosófico. En un segundo momento, atenderá al desarrollo y adiciones de sentido de esta epifanía a través de la continua aparición en sus obras. Así pues, analizará los ecos semánticos de estas imágenes, así como las referencias intertextuales e intratextuales de las mismas.

Palabras clave: eterno retorno - felicidad - cosas humanas

ABSTRACT: This paper explores the different aspects which made the intellectual experience that Nietzsche had when he heard the bells of Genoa. At first we consider the three semantic levels of this illumination: biographical, literary and philosophical. Then we explore the development and the additional meanings of this epiphany through the continued appearance in his works. Thus, we analyze the semantic echoes of these images, as well as references in and outside the text.

Keywords: Eternal return - Happiness - Human things

\section{DE SORRENTO A GÉNOVA}

El ocho de mayo de 1877, de vuelta a Basilea después de una estancia de seis meses en Sorrento, Nietzsche emprende el viaje a Génova. Esta primera estancia en Italia, que pasó con un pequeño grupo de amigos en la tranquila y encantadora península sorrentina, no le había devuelto la salud: los fuertes dolores de cabeza seguían atormentándole y la vista era todavía muy débil. Pero el sabático que le concedió la Universidad lo había como vuelto a sí mismo y le había hecho madurar un cambio decisivo en su vida y en su filosofía.

Cinco años antes el joven profesor de filología clásica de la Universidad de Basilea había escrito un libro titulado El nacimiento de la tragedia desde el espíritu de la música, que partiendo de una investigación sobre el origen de la tragedia griega proponía una reforma de la cultura alemana fundada sobre una metafísica del arte y sobre el renacimiento del mito trágico. Según esta contaminación original de genuinas hipótesis filológicas y elementos schopenhauerianos y wagnerianos, la existencia y el mundo pueden ser justificados solamente en 
cuanto fenómenos estéticos. El principio metafísico que forma la esencia del mundo, que Nietzsche llama lo «uno originario» (Ur-Eine), es de hecho eternamente sufriente y para liberarse de sus contradicciones necesita crear bellas representaciones oníricas. El mundo es el producto de estas representaciones artísticas no estetizantes, la invención poética de un dios sufriente y torturado, la imagen reflejada de una contradicción eterna. Estos seres humanos, según $E l$ nacimiento de la tragedia, son una representación de lo uno originario y cuando producen imágenes artísticas secundan y amplifican a su vez el impulso onírico y salvífico de la naturaleza ${ }^{1}$.

En realidad, ya en la época en la que escribía este libro, Nietzsche era consciente de que esta visión del mundo era solo una bella ilusión y tenía solamente un valor mítico en la lucha emprendida junto a Richard Wagner por una reforma de la cultura alemana. La primera etapa del pensamiento de Nietzsche está caracterizada de hecho por una profunda escisión entre lo que el joven profesor escribe públicamente y lo que dice en sus cartas y a sus estudiantes. Esta escisión terminará en 1878 cuando con la publicación de Humano demasiado humano², saldrán a la luz todo un conjunto de pensamientos que habían permanecido ocultos respecto a la actividad pública, dando la impresión de un cambio repentino y suscitando sorpresa y desconcierto en los amigos de Nietzsche que en gran parte compartían las ideas del movimiento wagneriano.

Desde el punto de vista humano los días de Sorrento hicieron también madurar una crisis. Por lo demás, incluso antes de partir hacia el Sur, Nietzsche había escrito en sus cuadernos: «He de manifestar en breve opiniones que se consideran ignominiosas para quien las sostiene; hasta los amigos y conocidos se mostrarán entonces esquivos y medrosos. También he de atravesar este fuego. Tras ello cada vez me perteneceré más a mí mismo» ${ }^{3}$. En Sorrento Nietzsche se reunirá por última vez con los Wagner que se habían instalado en el Sur para recuperarse del cansancio y de las decepciones de Bayreuth, y se habían alojado en el Gran Hotel Vittoria. La belleza del lugar y el sentimiento de una especie de tregua en la batalla no habían conseguido disipar sus preocupaciones. Ojeando los diarios de Cosima se percibe un sentimiento de fracaso, junto con la conciencia de una fuerte ruptura entre el sueño y su realización, la angustia por el futuro. Wagner superó este periodo de desasosiego retomando un proyecto que se remontaba a 1845 y que lo había esbozado de distintas maneras en los años sucesivos, en particular en un momento de profunda inspiración durante un viaje por los alrededores del lago de Zúrich en el viernes santo de 1857: escribir un drama sagrado dedicado a la figura de Parsifal.

Lejos de retornar a Feuerbach, Wagner pasaba de la metafísica schopenhaueriana a la religión cristiana. El 27 de octubre, el día en que Nietzsche y sus amigos llegaban a Sorrento, Cosima y Richard estaban inmersos en estos pensamientos. Por la tarde recibieron a los amigos en la terraza del Hotel Vittoria. Además de Nietzsche estaba su antigua amiga Malwida von Meysenbug, la autora de las Memorias de un idealista, que había seguido toda la parábola intelectual de Wagner pasando de Feuerbach a Schopenhauer, y el joven filósofo positivista

1. Cf. GT $\$ \$ 4$ y 5 y la posterior autocrítica en $\mathrm{Za} \mathrm{I}$, «De los que habitan el inframundo».

2. Sobre las razones por las que se traduce Menschliches, Allzumenschliches como Humano, demasiado humano, cf. nota 28.

3. FP II-1 101: 5[190], generalizado en MA $\$ 619$. 
Paul Rée, que no agradaba a los Wagner por sus orígenes judíos. Después de la visita, el matrimonio Wagner se entretuvo en la terraza escribiendo y meditando frente al mar y al bosquecito de olivos junto al hotel. Cosima anota en su diario: "Claro de luna sobre el olivar; pensamos en Cristo: 'Padre, si es posible aparta de mí este cáliz, pero que se haga tu voluntad'». Esta es la quintaesencia del dolor y de la redención. Cuántas veces el alma implora que le sea evitado el cáliz, qué difícil le es la resignación, qué raramente consigue soportarla, pero cuando lo consigue, cómo se le despliegan las alas, cómo se eleva a las alturas más puras, en donde ya nadie más la puede alcanzar» ${ }^{4}$. En la tierra en que los antiguos creían oír cantar a las sirenas, Nietzsche y Wagner se encontraron por última vez atraídos por melodías y pasiones entonces muy diversas. Fue probablemente en estos pocos últimos días en que vivieron cercanos cuando Wagner confesó a Nietzsche el éxtasis que experimentaba al pensar en el sagrado Grial y la última cena. Para Nietzsche fue la última gota: la bella amistad y solidaridad intelectual, la fraternidad de armas dentro del proyecto de Bayreuth para el renacimiento de la civilización helénica en Alemania gracias a la magia del teatro musical de Wagner terminaron en el Hotel Vittoria. Tranquilamente. Las relaciones se fueron enfriando: todo estaba ya claro, y todo se había terminado. El filósofo y el músico se atacaron públicamente: Nietzsche en Humano demasiado bumano, Wagner en un artículo en las Bayreuther Blätter titulado «Publico y popularidad», pero sin nombrarse explícitamente. Solo pocos días después de la muerte del compositor, en febrero de 1883, Nietzsche reveló a Malwida von Meysenbug qué es lo que había sentido después del festival de Bayreuth:

Wagner me ha ofendido mortalmente - iquiero que usted lo sepa! - su lento retorno a rastras al cristianismo y a la Iglesia lo he sentido como un insulto personal: toda mi juventud con sus aspiraciones me parecía contaminada porque había rendido homenaje a un espíritu capaz de este paso ${ }^{5}$.

Los Wagner se fueron a Nápoles y Nietzsche se quedó con sus amigos en Sorrento, en la villa Rubinacci. Sorprendido y desconcertado se reía de los planteamientos religiosos del maestro, pero con una risa amarga, como recordará más tarde:

Hubo un momento en que en secreto empecé a reírme de Richard Wagner, cuando él se preparó para su último papel y con gestos de taumaturgo, de nuncio de la salvación de profeta y hasta de filósofo, se presentó ante los alemanes. Y como yo todavía no había dejado de amarlo, mi propia risa me oprimió el corazón: como suele pasarle a quien se independiza de su maestro para encontrar su propio camino ${ }^{6}$.

Pero ¿cómo encontrar el propio camino, cómo aprender a caminar en solitario, sin Schopenhauer ni Wagner, y eventualmente contra ellos? A pesar de las

4. C. Wagner, Tagebücher. Ediert und kommentiert von Martin Gregor-Dellin und Dietrich Mack, München: Piper, 1976-1977, vol. 2, p. 1011.

5. CO V 324-325: a M. von Meysenbug, 21 de febrero de 1883; por lo que respecta a la «ofensa mortal», véase también la carta a Overbeck del día siguiente y la reconstrucción de Montinari en Su Nietzsche, Roma: Editori Riuniti, 1981, pp. 26-29.

6. FP III 870: 41[2]. 
pésimas condiciones de salud y de los dolores de ojos, Nietzsche comienza a escribir y se da cuenta de que ha llegado el momento de hacer públicas sus reflexiones subterráneas; no solo por medio de alusiones o insinuaciones, como había pasado en El nacimiento de la tragedia y en las Consideraciones intempestivas, sino de modo íntegro y coherente, desarrollándolas y completándolas con las nuevas ideas que se depositaban día a día en sus cuadernos, también gracias al diálogo con toda una serie de libros que había conseguido en los meses precedentes y que estaba leyendo junto con Paul Rée y con el pequeño círculo de amigos de la villa Rubinacci. Dedicado por las mañanas a escribir los primeros aforismos de su vida, aquellas opiniones ignominiosas de las que hablaba en el párrafo que hemos citado, Nietzsche decidió convertirse en filósofo. Renunciar a la filología y a la propaganda wagneriana, renunciar al modelo paradigmático de la Grecia antigua y enfrentarse de verdad a la actualidad, a la cultura de su época. Los bocetos de estos aforismos se encuentran en algunos cuadernos y en una carpeta llena de hojas sueltas que en el Archivo de Goethe-Schiller de Weimar llevan todavía el nombre de Sorrentiner Papiere $^{7}$. En esta tensión entre pasado y futuro, Nietzsche sueña a menudo con la infancia de las épocas precedentes de su vida, con personas que hacía tiempo había olvidado o estaban muertas, y le llega, casi como un testimonio exterior de este profundo cambio interior, la noticia de la muerte de su venerado maestro de filología, Friedrich Ritschl, de la abuela materna y de un colega suyo de la Universidad de Basilea. La filosofía, decía Schopenhauer, comienza con una reflexión sobre la muerte. Pero en medio de los Sorrentiner Papiere, enigmáticas y solitarias se encuentran estas palabras de Spinoza: «Homo liber de nulla re minus quam de morte cogitat et ejus sapientia non mortis sed vitce meditatio est $\rangle^{8}$. Si antes había escrito que solo el arte y la metafísica podían justificar las miserias humanas, en Sorrento Nietzsche comienza a pensar que la vida puede justificarse por sí misma, sin tener necesidad de inventar mundos y fines metafísicos.

Y sin embargo, qué difícil es soportar la vida en este viaje a Génova, a merced de un mar picado. Era el día de la ascensión, en alemán Himmelsfahrt, literalmente «viaje al cielo", y el filósofo escribe en una pequeña agenda en italiano: mare molto cattivo, y luego Höllenfahrt, es decir, «viaje al infierno». «En la nave todo giraba de un lado para otro y allí con gran ruido, las ollas saltaban y se animaban, los niños gritaban, la tempestad aullaba; mi destino era eterno insomnio, como diría el poeta». Así se describe ese viaje infernal en una carta escrita algunos días después, en la que medio en broma Nietzsche evoca también el pensamiento del suicidio:

A bordo del barco solo tenía los más sombríos pensamientos acerca del suicidio, únicamente me quedaba la duda acerca de dónde habría más profundidad para no volver a ser pescado de inmediato y tener que pagar una astronómica suma de oro por el rescate como muestra de gratitud ${ }^{9}$.

7. Nos referimos a la carpeta M XIV 1, a las libretas N II 1, N II 2 y N II 3 y a los cuadernos U II 5 y M I 1. Cf. la descripción de Montinari de los manuscritos de este periodo en KGW, IV/4: 102-105.

8. «En nada piensa menos el hombre libre que en la muerte y su sabiduría es una meditación, no sobre la muerte, sino sobre la vida», FP II 280: 19[68], cita de Spinoza, Ética, IV 67.

9. Agenda N II 8, con fecha 10 de mayo de 1877, transcrita en KGW, IV/4: 30; cf. CO III 213: 
A pesar de haberse encaminado sobre la vía de la aceptación de la existencia, el camino que debía hacer era todavía muy largo. Las cartas de Sorrento que lleva en la maleta y el proyecto de un nuevo libro sin título todavía son una promesa de libertad, pero también una tarea gravosa. ¿Tendrá todavía la suficiente fuerza y coraje para escribirlo y publicarlo? ¿No sería mejor renunciar a ello? Y cuando al despuntar el alba divisa las luces del puerto de Génova, piensa palabras más oscuras de las que luego enviará por carta:

Deseo de la muerte, como tiene deseo de la tierra el que mareado ve al alba las luces del puerto.

Este pensamiento aflora en un cuaderno escrito en tierra firme en Génova, probablemente al día siguiente, el once de mayo, y está escrito en la misma página de otra nota que nos interesa ahora: «Toque de campanas en Génova melancólico, horrendo, infantil. Platón: nada de lo que es mortal es digno de gran seriedad $»^{10}$.

Caminando por las calles de Génova a la hora del crepúsculo, Nietzsche había escuchado el sonido de las campanas que provenían de lo alto de una torre. En un instante los recuerdos del hijo del pastor, la erudición del filólogo y la reflexión se habían fundido en una experiencia intelectual que lo había conmocionado profundamente y de la que esta página conserva el primer registro escrito.

\section{EL VALOR DE LAS COSAS HUMANAS}

Hay al menos tres niveles semánticos que se entrecruzan en esta súbita iluminación: un nivel biográfico, uno literario y otro más propiamente filosófico. Desde el punto de vista biográfico, el sonio de las campanas, que silabea las horas del día y acompaña a las funciones religiosas, había hecho emerger una avalancha de recuerdos desde las profundidades del alma de Nietzsche, hijo del pastor de la pequeña aldea de Röcken. En las autobiografías y en las poesías juveniles se encuentran numerosas huellas de la impresión profunda que el sonido de las campanas ejercía sobre él, a menudo evocado con palabras semejantes a las de la epifanía genovesa.

En 1858, con catorce años, Nietzsche describe la aldea de Röcken y la feliz época de su infancia de la que el campanario y el sonido de las campanas son la representación visual y sonora ${ }^{11}$, asociados a la imagen del padre y a su papel en la comunidad. Son recuerdos antiguos y profundos que explican por qué en el sonido

a M. von Meysenbug, 13 de mayo de 1877.

10. "Glockenspiel Abends in Genua - wehmütig schauerlich kindisch. Plato: nichts Sterbliches ist grossen Ernstes würdig». Libreta N II 2, p. 4. El facsímil de esta página está publicado en F. Nietzsche, Digitale Faksimile Gesamtausgabe, ed. de P. D’Iorio, Nietzsche Source: Paris 2009-, http:// www.nietzschesource.org/DFGA/N-II-2,4; la transcripción de los dos fragmentos se encuentra respectivamente en KGW IV/4 451 y 240. Sobre las campanas de Génova he escrito por primera vez en "Aucune des choses humaines n'est digne du grand sérieux. Notes sur la genèse de l'aphorisme 628 de Choses humaines, trop humaines de Friedrich Nietzsche»: Euvres et critique XXV 1 (2000), $107-$ 123; este tema ha sido retomado por O. Ponton, Philosophie de la légèreté, Berlin/New York: Gruyter, 2007, pp. 46-81.

11. Cf. KGW I/1 302: 4[77]. 
de las campanas Nietzsche oye resonar toda la melancolía (una de las palabras que hemos encontrado en la nota sobre las campanas) de la infancia perdida.

Por encima de todo sobresale el campanario recubierto de musgo. Recuerdo todavía aquella vez que había ido con mi amado padre de Lützen a Röcken, y a mitad del camino las campanas habían comenzado a tocar anunciando con solemnes retoques el día de Pascua. Este sonido me viene a veces a la memoria, y ide repente la melancolía me lleva a la querida casa paterna lejana! ${ }^{12}$.

Desgraciadamente, poco después de una año de aquel viaje feliz, Nietzsche no había todavía cumplido cinco años, las campanas a muerto acompañaron el cuerpo de su padre. A aquel sonido que representaba la felicidad infantil, la casa, la familia, se asocia entonces el horror de la muerte y la separación de los lugares queridos: «La ceremonia comenzó a la una de la tarde, con el sonido de todas las campanes. iOh, no se devanecerá nunca más de mi oido su sonido oscuro»; «iCómo me conmovió el funeral! iCómo traspasó el corazón el toque sórdido a muerto!»13. En las cartas y en las poesías de este periodo también se asocia el sonido de las campanas a la muerte. Por ejemplo, en una poesía de 1861 titulada, La vigilia del día de los muertos, en el que el sonido de las campanas en la noche invernal despierta la memoria de los queridos difuntos que dormían en lo profundo del corazón. El pobre, loco corazón se espanta, mientras el sonido pleno y cálido de las campanas penetra en su gélida profundidad, para que los muertos se despierten e inviten al muchacho a reencontrarlos en su frío y largo sueño ${ }^{14}$. Desde un punto de vista biográfico, por lo tanto, el sonido de las campanas es melancólico e infantil, porque en él resuena el mundo de la infancia perdida; y es horrendo porque está asociado al pensamiento de la muerte. Las campanas atraviesan el corazón que conserva el recuerdo de los difuntos.

Esta precoz experiencia individual, se filtra progresivamente en toda una serie de reminiscencias literarias. Como se sabe, la campa a muerto resonaba en el muy célebre Canto de la campana de Schiller: «Desde la catedral, / grave y lúgubre, / toca la campana / un canto fúnebre. Sus tristes repiques acompañan seriamente / el último viaje del viandante» ${ }^{15}$. Y Goethe, en el Epílogo a la campana de Schiller, había tomado el motivo de la campana para recordar la muerte del amigo: "Oigo horribles repiques de campana a medianoche, / sonidos tristes tañen pesados y sombríos. / ¿Es posible? ¿Es ciertamente por nuestro amigo?» ${ }^{16}$. Leyendo Los dos

12. KGW I/1 283: 4[77].

13. KGW I/2 3: 5[1]; KGW I/1 286: 4[77].

14. NF 1862 14[29].

15. Schiller, Das Lied von der Glocke (1800), vv. 244 ss.: «Von dem Dome / Schwer und bang / Tönt die Glocke / Grabgesang», en el que las tres vocales «o y a» se alternan imitando el triste sonido de la campana fúnebre. Nietzsche conocía esta célebre poesía de Schiller al menos desde las celebraciones del centenario schilleriano en Pforta en 1859, cuando había participado como corista en las pruebas de la versión en forma de cantata sobre la música de Andreas Romberg, cf. NF 1859 7[3]124 y la carta a la madre de mediados de noviembre de 1859. Paul Deussen recuerda haber declamado la Campana de Schiller en Pforta, mientas Nietzsche improvisaba un acompañamiento al piano (P. Deussen, Ricordi di Friedrich Nietzsche, Napoli: La scuola di Pitagora, 2010, p. 58).

16. J. W. v. Goethe, Epilog zu Schillers Glocke (1805), vv. 9 ss., en Tutte le poesie, II/1, p. 831; también el Epilogo de Goethe formaba parte de las celebraciones schillerianas: Nietzsche lo cita lue- 
Foscari de Byron en 1861, Nietzsche queda impresionado por la figura del viejo dux que muere súbitamente cuando oye la campana de San Marcos anunciando la elección de su sucesor, «la campana fúnebre que ya solo suena por la muerte de un príncipe». Dos años después, Nietzsche vuelve a utilizar este motivo en una poesía dedicada al quincuagésimo aniversario de la batalla de Leipzig para expresar la inquietud de Napoleón que, oyendo tocar las campanas a muerto, como viejo dux piensa en el fin de su parábola política y en la muerte: «Los campanarios de Leipzig vuelven a tocar ahora, / un canto fúnebre en el día de los difuntos / [...] ¿ Oís vosotros, mis generales? / El corazón roto de un $d u x$ se rompió/ iun día para este orgulloso repique de campanas! / Mi corazón también oye un canto terrible / ¿'Tendrá que romperse? iDadme un consejo!» ${ }^{17}$.

En sus cartas sobre el teatro alemán, Heinrich Heine había tratado la imagen sonora de la muerte utilizando los mismos términos de la epifanía nietzscheana:

En otoño el sonido de las campanas es todavía más serio [ernster], aún más horrible [schauerlicher], parece sentir la voz de un fantasma. Especialmente durante un funeral el sonido de las campanas produce un eco de una manera indeciblemente melancólica [wehmütigen]; cada vez que repican hojas amarillas enfermas caen del árbol, y este sonoro caer de las hojas, esta imagen sonora de la muerte [Sterbens] me llenó una vez de una tristeza tan profunda que me puse a llorar como un niño. Ha sido el año pasado cuando Margot ha enterrado a su marido... ${ }^{18}$.

La alusión a la seriedad, Ernst, del sonido de las campanas estaba presente también en los versos de Schiller que hemos citado más arriba y volvía en las estrofas conclusivas en las que la campana, desde lo alto de la torre de la catedral, nos recuerda la vanidad de las cosas humanas respecto a la seriedad y a la eternidad de las cosas celestes:

En lo alto, por encima de las ínfimas existencias terrenas

hermana del trueno debe librarse en el cielo azul

[...] Solo a las cosas serias y eternas

se consagra su boca metálica

[...] Es como el sonido vigoroso que de ella emana

se desvanece y desaparece en nuestros oídos,

así puede la campana enseñar

que pasa y no dura todo lo que es mortal ${ }^{19}$.

En estos ejemplos ilustres Nietzsche encuentra un vocabulario común y casi un topos literario que le permite expresar una experiencia originariamente limitada a la esfera individual de manera más general y compartida.

El tercer elemento confiere a esta nota su significado más propiamente filosófico uniendo la imagen biográfica y literaria de la campana, símbolo sonoro de

go en BA I, IV, en DS, $\$ 4$ y en un apunte de 1879: «Cuando leo las palabras de Goethe sobre Schiller, 'y tras él, en apariencia irreal, etc.', he de echarme a llorar. ¿̇or qué?», FP II-1 466: 41[68].

17. Cf. Lord Byron, I due Foscari, acto IV y FP I 12[4] y 16[2].

18. H. Heine, Über die französische Bühne. Vertraute Briefe an August Lewald, en Sämtliche Werke, Hoffmann und Campe, vol. I, p. 133. Nietzsche cita esta obra en la carta a Rohde del 8 de octubre de 1868 .

19. F. Schiller, loc. cit., vv. 403 ss. 
la muerte y de la fragilidad de las cosas humanas, con la desvalorización de la existencia contenida en las palabras de Platón. En el séptimo libro de su diálogo, Las Leyes, Platón habla de la educación de la juventud y propone una serie de enseñanzas para hacer bellos y virtuosos los cuerpos y las almas de los jóvenes. Luego, casi sintiendo el peso de todo este trabajo de minuciosa reglamentación de algo que en sí no es digno de tanto esfuerzo, se abandona a una reflexión mucho más general y escribe: «En realidad los asuntos de los hombres no son dignos de ser tratados con tanta seriedad; pero es necesario tomarlos en serio, aunque no sea un placer hacerlo». Y luego se explica mejor: «Digo que debemos ocuparnos de aquello que es serio y de lo que no es serio. Lo divino es por su naturaleza digno de seriedad, mientras que el hombre es solamente un juguete fabricado por los dioses $»^{20}$. Platón también expresaba la misma idea en un pasaje de la República que recoge luego Schopenhauer en Parerga y paralipomena:

Quien ha acogido plenamente en sí misma la doctrina de mi filosofía, y sabe por lo tanto que toda nuestra existencia es algo que mejor que no existiese, desde el momento que la más grande sabiduría consiste en negarla y en refutarla, no nutrirá ni siquiera grandes esperanzas respecto a alguna cosa y alguna situación, no aspirará apasionadamente a nada que pertenezca a este mundo, no lanzará grandes lamentos por haber fracasado en alguno de sus fines, pero habrá asimilado plenamente la frase de Platón ${ }^{21}$ :

$\varpi$

$\mu \quad$ ш 22.

Por el testimonio de Albert Brenner sabemos que en Sorrento, en diciembre de 1876, durante las sesiones de lectura en común, se leían Las leyes de Platón. Y las palabras de Platón: «Todo lo que es humano no es digno de gran valor» se encuentran también, aisladas y enigmáticas, en un cuaderno de Sorrento ${ }^{23}$. Pero ya algunos meses antes de ir a Sorrento, mientras impartía en la universidad un curso sobre los conceptos fundamentales de la filosofía platónica, en sus apuntes personales Nietzsche se pregunta sobre la validez de la metafísica del arte:

iSi Platón tuviese razón! iSi el hombre fuese un bonito juguete en manos de los dioses! [...] iSi la existencia no fuese otra cosa que un fenómeno estético! Entonces el artista no solo sería el hombre más sabio y racional, y sería lo mismo que el filósofo, pero tendría una vida fácil y ligera y podría decir con buena conciencia, como Platón: las cosas humanas no son dignas de una gran seriedad [die menschlichen Dinge sind grossen Ernstes nicht werth $]^{24}$.

Si Platón tuviese razón... Según El nacimiento de la tragedia Platón tenía razón: el hombre era un juguete en las manos de los dioses, la existencia era justificada

20. Platón, Leyes, 803b-d, cf. también 644d.

21. Platón, República, X, 604.

22. A. Schopenhauer, Parerga y paralipomena I, p. 552.

23. Cf. la carta de Albert Brenner del 4 de diciembre de 1876 en C. A. Bernoulli, Franz Overbeck und Friedrich Nietzsche, Jena: Diederichs, 1908, I, p. 202; la nota citada se encuentra en la página 64 de la libreta N II 3: «Alles Menschliche insgesamt ist keines grossen Ernstes werth» (facsímil en DFGA/N-II-3,64).

24. F. Nietzsche, «Über den Rhythmus (1875)», Gesammelte Werke, München: Musarionausgabe, 1922, vol. V, pp. 475-476. El pasaje de Platón se cita también en FP II 144: 9[1] en otro contexto. 
solo como fenómeno estético y el artista era el producto más alto de la naturaleza. Y si podía aceptar que las cosas humanas no valiesen nada, porque sin embargo existía otra dimensión, la dimensión metafísica, que justificaba la vida. Pero en este fragmento de 1875, Platón ya no tiene razón. El fragmento se cierra diciendo que el arte sirve propiamente para transfigurar una vida que no tiene valor. «¿La existencia del arte no demuestra propiamente que la vida es un fenómeno antiestético, malvado y serio? Considérese sin embargo lo que dijo una vez un pensador serio, Leopardi». El pesimismo de Giacomo Leopardi es entonces para Nietzsche más profundo que el pensamiento de Platón, porque está exento de ilusiones transcendentes $^{25}$. No hay una dimensión metafísica que se pueda librar del pesimismo y que nos permita tomar a la ligera la falta de valor de las cosas humanas. Nada de lo que es humano tiene valor, y lo divino no existe.

Después de Génova Nietzsche continua el año sabático en Rosenlauibad, en los Alpes berneses, y continúa leyendo La leyes de Platón. El sonido de las campanas de la aldea, el domingo por la mañana, produce en el filósofo perdido en sus meditaciones un efecto de extrañamiento, como algo que viniese de muy lejos, como un fragmento de antigüedad. Y escribe en su cuaderno: «Por la mañana suenan las campanas -Alpes berneses- en honor de un judío crucificado, que decía que era el hijo de Dios». La versión publicada de este texto, termina con: «iQue viento horrible nos manda todo eso, como desde el sepulcro de un antiquísimo pasado! ¿Quién creería que una cosa semejante es todavía creída?» ${ }^{26}$. Si las campanas de Génova representaban el horror de la muerte y el nihilismo de Platón, en las de Rosenlauibad Nietzsche oye resonar el error de la fe y el platonismo de los pobres: el cristianismo.

Detengámonos por un instante para hacer un balance provisional sobre el sentido de esta breve nota genovesa. Nietzsche ha utilizado aquí algunos términos que, además de su significado literal, también actúan como palabras clave, como precisas referencias intertextuales. El filósofo esperaba que un buen lector, un contemporáneo erudito, leyendo "campanas» sintiese resonar las palabras de Byron, Goethe, Schiller, Heine, y leyendo sobre la falta de valor de las cosas humanas pensase en Platón, Schopenhauer, Leopardi y en la doctrina cristiana. Con dos frases escritas a lápiz en su cuaderno, Nietzsche suelda el topos literario de las campanas a la desvalorización de la existencia contenida en las palabras de Platón y las condensa en una imagen simbólica a la que atribuye un preciso sentido filosófico: la campana como símbolo extremo el pesimismo, del nihilismo y del cristianismo. Nosotros con posterioridad, aunque no es estrictamente necesario para la comprensión del texto, podemos además leer ahí una referencia a la infancia de Nietzsche y a la muerte del padre, como son narradas en las poesías y en las autobiografías juveniles. Nosotros como posteridad tenemos también el privilegio de seguir la historia textual, el desarrollo genético de esta anotación en los cuadernos de Nietzsche. Podemos por lo tanto tratar de comprender no solo cómo Nietzsche ha compuesto esta imagen simbólica, sino también cómo luego la utilizará en su obra. Como veremos, Nietzsche potenciará posteriormente el

25. Nietzsche había citado a Leopardi precisamente en este sentido en la segunda Intempestiva: «Non val cosa nessuna / I moti tuoi, né di sospiri è degna / La terra. Amaro e noia / La vita, altro mai nulla; e fango è il mondo. / T'acqueta omai» (G. Leopardi, «A se stesso», citado en HL $\mathbb{1 1 2}$, OC I 697).

26. HH $\$ 113$. 
campo semántico de esta imagen gracias a la posición que ocupará en sus textos y a la relación que establecerá con otras imágenes simbólicas.

\section{GÉNESIS ENTRELAZADAS}

Intentemos por tanto seguir el desarrollo y las adiciones de sentido de esta epifanía a través de sus reescrituras. En Rosenlauibad, reminiscencia de la tradición literaria, Nietzsche intenta reelaborar en versos la intuición de Génova. Esta reescritura poética se centra en tres adjetivos clave (melancólico, horrible, infantil) e introduce un juego de palabras entre Glockenspiel y Glockenernst, «sonido de campanas» (literalmente «juego de campanas») y «seriedad de campanas», pero le falta la referencia a Platón.

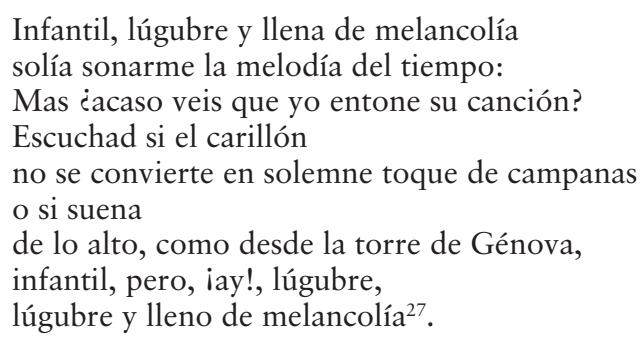

De vuelta a Basilea, Nietzsche trabaja en la escritura de su nuevo libro y la epifanía de las campanas vuelve a cruzarse con las palabras sobre el deseo de la muerte. Los dos apuntes nacidos en la misma página del cuaderno de Sorrento vuelven a ser copiados en el mismo folio, el número 222 de una carpeta de folios sueltos destinados a Humano demasiado humano; aquel sobre las campanas de Génova es titulado Alles Menschliches insgesamt, todo lo que es humano, y el del suicidio, Sensucht nach dem Tode, anhelar la muerte.

Todo lo que es humano. Una tarde en Génova oí un sonido de campanas que provenía de lo alto de una campanario: era algo tan nostálgico, horrible y melancólico que sentí aquello que decía Platón: «todo lo que es humano no es digno de gran seriedad».

Anhelo de la muerte. - Como el que está mareado otea la costa desde el barco con los primeros claros de la mañana, así anhela uno con frecuencia la muerte - a sabiendas de que no se puede alterar ni la marcha ni el rumbo del barco ${ }^{28}$.

La diferencia más palmaria en esta reelaboración es el uso del término Menschliches, lo que es humano, en lugar del originario Sterbliches, lo que es mortal,

27. «Kindisch und schaurig und wehmutsvoll / klang die Weise der Zeit mir oft: / sehet nun sing ich ihr Lied? / hört, ob das Glockenspiel / nicht sich verwandelt in Glockenernst / oder ob es klingt / hoch herab wie vom Genua-Thurm. / Kindisch jedoch ach schaurig / Schaurig und wehmutsvoll» (FP II-1 313: 22[45]).

28. Facsímil en DFGA/Mp-XIV-1,222; el primer apunte es transcrito en KGW IV/4 240, el segundo es el FP II-1 365: 23[188], cf. también FP II-1 368: 23[197]. 
que hace pensar que Nietzsche haya vuelto a coger el texto de Platón. Y quizás es precisamente en esta ocasión en la que subrayado las palabras

$\mu \quad \varpi \quad$ en su ejemplar personal de la República ${ }^{29}$. En la siguiente etapa genética hay dos importantes modificaciones. El aforismo sobre el suicidio desaparece: ya no será transcrito ni siguiera publicado por Nietzsche. Contemporáneamente, Nietzsche añade un pointe al aforismo sobre las campanas, en el sentido técnico de término final en el que se concentra el efecto que el aforismo quiere tener. Este término final es el adversativo trotzdem (sin embargo, no obstante, a pesar de), que se convierte también en el título del aforismo.

Sin embargo. - En Génova, a la hora del crepúsculo, oí llegar desde una torre un prolongado sonido de campanas: no quería terminar y resonaba como insaciable de sí mismo, por encima del ruido de los vehículos en el cielo de la tarde y en el aire del mar, tan horrendo, y al mismo tiempo tan infantil, tan melancólico. Entonces me acordé de las palabras de Platón y las sentí de repente en el corazón: todo lo que es humano no es digno de gran seriedad, sin embargo _ _ ${ }^{30}$.

En lugar de limitarse a expresar toda la angustia de la desvalorización del mundo, del error, de la muerte, la angustia de la condición humana respecto a la visión de la eternidad atemporal imaginada por Platón y por el Cristianismo y a través de ellos de toda la tradición filosófica occidental, Nietzsche acepta el desafío. Añade un trotzdem: nada tiene valor, todo es vano, pero... Aceptar el desafío significa también renunciar al suicidio y esto explica por qué la génesis del aforismo sobre la nostalgia de la muerte se haya interrumpido precisamente en este punto. El siguiente paso en la génesis introduce una ulterior modificación textual y estructural, muy elocuente. En el manuscrito enviado a la imprenta este aforismo sobre la vanidad de las cosas humanas será titulado Epílogo y se pondrá en la última página de un libro que no por casualidad llevará el título de Menschliches, Allzumenschliches, Humano demasiado humano ${ }^{31}$.

El aforismo, y el libro sobre las cosas humanas, terminan por lo tanto con un adversativo que queda en suspenso y es seguido por dos Gedankenstriche, dos guiones suspensivos. En la escritura de Nietzsche el guión largo es una estrategia de reticencia que sirve para distinguir el contenido más superficial del pensamiento del más profundo e invita al lector a meditar el aforismo. Tiene por lo tanto un doble efecto: «por un lado empuja hacia adelante el razonamiento anunciando su giro repentino, por otro lado 'se aleja', obligando al lector a retornar sobre aquello que hace poco ha leído, rumiándolo y reinterpretándolo a la luz de un nuevo dato ${ }^{32}$. Los dos guiones largos puestos al final nos invitan

29. El ejemplar que tenía Nietzsche se conserva en la Herzogin Anna Amalia Bibliothek de Weimar, en el lugar C 63-b; el subrayado se encuentra en la página 298 y es uno de los rarísimos subrayados que tiene ese volumen.

30. Facsímil en DFGA/Mp-XIV-1,114.

31. Facsímil del manuscrito para la imprenta en DFGA/D-11,213 e 214. El epílogo es también una referencia al goethiano Epílogo a la campana de Schiller.

32. E. Mengaldo, «Strategie di reticenza e demistificazione: il trattino di sospensione negli aforismi di Friedrich Nietzsche», pp. 45 y 37. Sobre el uso de los guiones largos y, más en general, sobre las formas de la aposiopesis en Nietzsche y sobre el influjo de los moralistas franceses y de Laurence Sterne, véase el análisis de V. Vivarelli (Nietzsche und die Masken des freien Geistes. Mon- 
por tanto a volver a leer no solo el aforismo sino todo el libro a la luz de las campanas del nihilismo, insertándolo así en una arco de tensión filosófica que se remonta a Platón y a toda la tradición pesimista, y considerando que «sin embargo", trotzdem, debe ser para nosotros un modo de dar valor a las cosas humanas. Humano demasiado humano habla precisamente de esto: toma de posición contra Platón, contra el pesimismo, y propone esbozos de una visión alternativa: química de las ideas y de los sentimientos, confianza en la historia y en la ciencia, epicureísmo, inocencia del devenir, revalorización de las cosas próximas...

\section{LA CAMPANA AZUL DE LA INOCENCIA}

Las aventuras de la génesis del aforismo sobre las campanas de Génova todavía no han terminado. Durante la corrección de los borradores Nietzsche añade diez aforismos antes del Epílogo que en las segundas pruebas toma el numero $638^{33}$. Luego, sin embargo, en el último momento cambia el aforismo 638 con el 628 y el aforismo sobre las campanas pierde así su posición final. Consecuentemente Nietzsche cambia también el título del aforismo que de Epilog se convierte en Spiel und Ernst, juego y seriedad - jugando con el hecho de que en el aforismo resuena un Glockenspiel, literalmente un «juego de campanas»-y luego, continuando con el juego de palabras, encuentra el título definitivo de lo que será el aforismo 628 de Humano, demasiado humano: Ernst im Spiele, Seriedad en el juego. ¿Por qué Nietzsche cambia estos dos aforismos? Avancemos dos hipótesis: para confundir las huellas y hacer más difícil la percepción del efecto de eco entre el Menschliches del título y el de las campanas. Puede parecer extraño, pero Nietzsche practica y teoriza la idea de darse de las simetrías y luego de esconderlas y no respetarlas del todo: «Mi estilo es una danza, un juego de simetrías de todo tipo y al mismo tiempo un ignorar y burlarse de estas simetrías» ${ }^{34}$; o, más probablemente, por la voluntad de terminar el libro con la campana de mediodía más bien que con la campana de la tarde. De hecho el último aforismo, titulado el caminante, se cierra con la imagen de los caminantes y los filósofos que «meditan cómo el día, entre el décimo y el duodécimo toque de campana, pueda tener un rostro tan puro, tan luminoso, tan transfigurado y sereno: buscan la filosofía de la mañana». De este modo, incluso manteniendo una referencia intertextual a las campanas, Nietzsche da un carácter más afirmativo a la clausura del libro y refuerza indirectamente el trotzdem contenido en el aforismo 628. El último aforismo anticipa además la imagen del vagabundeo intelectual y de la filosofía de la mañana que encontrarán luego expresión en El viajero y su sombra y en Aurora y los temas de la felicidad meridiana y de la campana azul que serán desarrollados en Asi habló Zaratustra.

La imagen de la campana azul también es antigua y se remonta a las primeras lecturas filosóficas del Nietzsche adolescente. En las páginas de la Conducta

taigne, Pascal und Sterne, Würzbug: Königshausen und Neumann, 1998, pp. 159 ss. y 25 ss.), que cita entre otros el fragmento FP III 34[147], en el que Nietzsche dice que prefiere sus guiones largos de suspense que los pensamientos formulados de manera completa.

33. Cf. el facsímil en DFGA/K-4,377.

34. Carta a Rohde del 22 de febrero de 1884, CO IV 438. 
de la vida de Ralph Waldo Emerson, Nietzsche había encontrado la descripción de la campana de cristal del horizonte celeste.

De niños nos creíamos encerrados por el horizonte como por una campana de vidrio y no dudábamos poder alcanzar, caminando ininterrumpidamente, el lugar en el que el sol y las estrellas se sumergen en el agua. En realidad el horizonte huye ante nosotros y nos deja en un vacío sin fin, que no está protegido por ninguna campana de cristal. Sin embargo es singular con qué fuerza nos agarramos a aquella astronomía de la campana, a la imagen de un horizonte familiar que nos abraza y nos protege ${ }^{35}$.

El filósofo utilizará estos rasgos emersonianos para expresar su doctrina de la inocencia del devenir, comparándola con una campana azul que protege la vida de las interpretaciones erróneas y nocivas de la metafísica y de la teleología. La campana celeste de la inmanencia nos vuelve a asegurar y a dar la serenidad de quien sabe que no existe nada más allá de nuestro mundo terreno: ningún dios, ninguna dimensión metafísica, ninguna schopenhaueriana voluntad de vivir; y que en el devenir no se manifiesta ni la providencia cristiana, ni la racionalidad hegeliana, ni una tendencia, moral o biológica, hacia un fin último, como por el contrario sostenían aquellos que eran considerados entre los más grandes filósofos de la época: Hartmann, Dühring y Spencer. La doctrina de la inocencia del devenir equivale a una bendición del mundo, porque solamente si no existe una dimensión metafísica o teleológica la existencia recupera todo su valor. En el capítulo Antes de la salida del sol, del tercer Zaratustra, el sabio persa explica el efecto tranquilizador y bendecidor de su doctrina de la inmanencia con estas palabras:

Pero esta es mi bendición: estar yo sobre cada cosa como su cielo propio, como su techo redondo, su campana azul y su eterna seguridad: ibienaventurado quien así bendice! [...]

En verdad, una bendición es y no una blasfemia el que hoy enseñe: «Sobre todas las cosas está el cielo Azar, el cielo Inocencia, el cielo Acaso y el cielo Arrogancia».

"Por acaso» ${ }^{36}$ - esta es la más vieja aristocracia del mundo, yo se la he restituido a todas las cosas, yo la he redimido de la servidumbre a la finalidad.

Esta libertad y esta celestial serenidad yo las he puesto como campana azul sobre todas las cosas al enseñar que por encima de ellas y a través de ellas no hay ninguna «voluntad eterna» que - quiera.

El sentimiento de felicidad de este mundo perfecto en sí mismo, que no tiene necesidad de tender a un fin o de obedecer a un principio moral, se expresa con imágenes y palabras emersonianas. En sus Ensayos, Emerson había descrito

35. R. W. Emerson, Die Führung des Lebens. Gedanken und Studien, Leipzig: Steinacker, 1862, pp. 185 s., libro que Nietzsche ha utilizado en sus primeros escritos filosóficos de 1862 sobre el fatum, la historia, la libertad, y que no se ha cansado nunca de releer; cf. B. Zavatta, La sfida del carattere. Nietzsche lettore di Emerson, Roma: Editori Riuniti, 2006, sobre todo pp. 40 ss., y V. Vivarelli, L'immagine rovesciata, cit., pp. 152-153.

36. Obsérvese cómo Nietzsche utiliza la expresión «von Ohngefähr», que tiene el sonido de un nombre noble (partícula von). Cf. en la Biblia, Sabiduría 2,2, donde - en la traducción de Luterose lee con la misma expresión: «hemos nacido por casualidad» (Montinari, aparato crítico de Así habló Zaratustra, en Opere, Milano: Adelphi, 1982, vol. VI/1, p. 465). 
los momentos de pánico cuando el mundo alcanza la perfección y el hombre la felicidad:

En casi cada estación del año sucede que en este clima hay días en los que el mundo alcanza su perfección; cuando el aire, los cuerpos celestes y la tierra tienen una única armonía, como si la naturaleza quisiese acariciar a sus criaturas [...] El día infinitamente largo, duerme sobre las amplias colinas y sus grandes campos calientes.

A Nietzsche le impactó esta imagen y la había recogido en una carta a su amigo Gersdorff:

Querido amigo: de vez en cuando llegan las horas de esa contemplación serena, cuando en una mezcla de alegría y tristeza uno trasciende su propia vida, como en esos hermosos días de verano, tan maravillosamente descritos por Emerson, que caen ancha y dulcemente sobre las colinas: es entonces cuando la naturaleza alcanza, como él mismo dice, su entera perfección. ¿Y nosotros? Nosotros entonces somos libres del hechizo de una voluntad cada vez más vigilante, nosotros ya no somos sino un ojo puro, contemplativo, libre de todo interés ${ }^{37}$.

En esta carta de juventud Nietzsche interpreta la imagen de Emerson en clave schopenhaueriana, como momento de quietud de la voluntad de vivir y de pura contemplación del sujeto cognoscente. En el capítulo Mediodía del cuatro libro de Zaratustra vuelve la imagen, depurada de la interpretación schopenhaueriana, imbuida de un sentimiento clásico de estupor y de pánico, y unida a la sensación de un instante de breve e intensa felicidad:

iSilencio! iSilencio! ¿No se ha vuelto perfecto el mundo en este instante? ¿Qué es lo que me ocurre? [...]

¡Oh felicidad! iOh felicidad! ¿Quieres acaso cantar, alma mía? Yaces en la hierba. Pero esta es la hora secreta, solemne, en que ningún pastor toca la flauta.

iTen cuidado! Un ardiente mediodía duerme sobre los campos. iNo cantes! iSilencio! El mundo es perfecto.

[...] El viejo mediodía duerme, mueve la boca: ¿no bebe en este momento una gota de felicidad -

— una vieja, dorada gota de áurea felicidad, de áureo vino? Algo se desliza sobre él, su felicidad ríe $e^{38}$.

\section{EL CANTO NOCTURNO DE ZARATUSTRA}

En dos capítulos clave de la tercera y cuarta parte de Así habló Zaratustra vuelve la campana del nihilismo. En el capítulo, La segunda canción de danza, penúl-

37. Carta a Gersdorff, 7 de abril de 1866, CO I 381. La referencia a R. W. Emerson está en el capítulo «Natur» de los Versuche, Hannover: Carl Meyer, 1858, pp. 391-392. Cf. A. Schopenhauer, El mundo como voluntad y representación, trad., introd. y notas de Pilar López de Santa María. Madrid: Trotta, vol. I, ${ }^{2} 2009$, $\mathbb{S} 34$. La imagen emersoniana aparece también en el fragmento FP II-1 45[1].

38. La relación entre el mediodía y la felicidad se encuentra también en el aforismo 308 de WS y volverá en los ditirambos El sol se pone (DD). Sobre las fuentes griegas puede verse K. Schlechta, Nietzsche e il grande meriggio, Nápoles: Guida, 1998, pp. 51 ss. 
timo de la tercera parte, la campana del nihilismo aparece bajo la forma de una vieja campana de medianoche y como en el cuaderno de Génova es acompañada por el deseo de la muerte. La vida se dirige a Zaratustra y, pensativa, le dice en voz baja:

¡Oh Zaratustra, tú no me eres bastante fiel!

No me amas ni mucho menos tanto como dices; yo lo sé, tú piensas que pronto vas a abandonarme.

Hay una vieja, pesada, pesada campana retumbante: ella retumba por la noche y su sonido asciende hasta tu caverna: -

cuando a medianoche oyes dar la hora a esta campana tú piensas en esto entre la una y las doce, -

tú piensas en esto, oh Zaratustra, yo lo sé, ien que pronto vas a abandonarme!

Pero esta vez, frente a la campana del nihilismo, Nietzsche no se limita a formular una tímida objeción, a añadir un trotzdem. Finalmente ha encontrado una respuesta a las palabras de Platón. Antes le susurra al oído de la vida:

«Sí̀, contesté yo titubeante, «pero tú sabes también esto».

Y le dije algo al oído, por entre los alborotados, amarillos, insensatos mechones de su cabello

«¿Tú sabes eso, oh Zaratustra? Eso no lo sabe nadie» - -

Y luego Zaratustra enuncia, mejor dicho, canta su respuesta sobre las doce campanadas del nihilismo. Así pues, las palabras de Platón ya no acompañan el sonido de las campanas, sino el canta de Zaratustra.

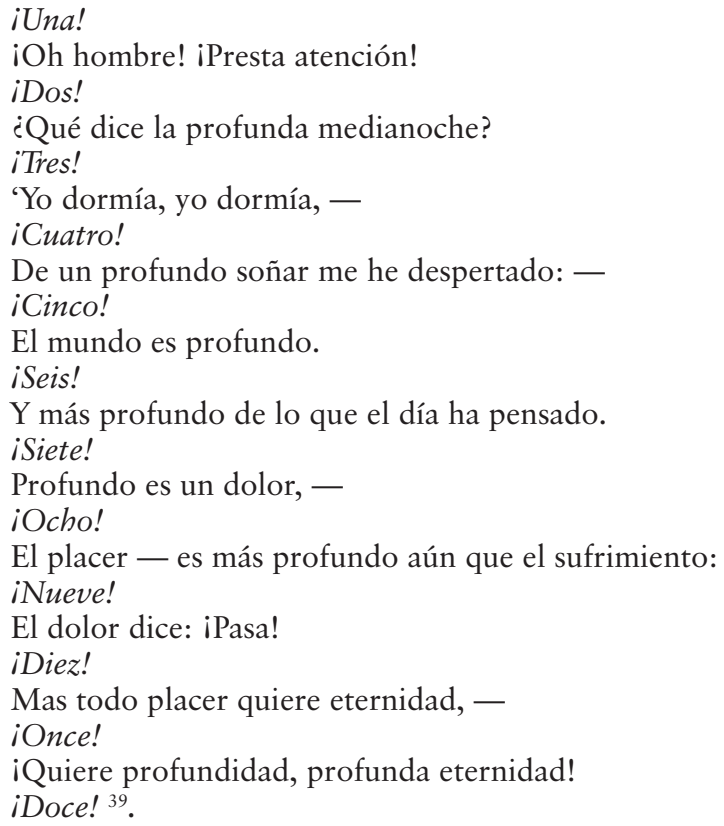

39. Como ha observado Peter André Bloch («Aus meinem Leben’. Der selbstporträtcharakter von Nietzsches frühen Lebensbeschreibungen: Selbstdialog als Selbstbefragung»: Nietzscheforschung 2 
Zaratustra es el maestro del eterno retorno y por lo tanto la respuesta a las palabras de Platón es la doctrina del eterno retorno de lo mismo. Pero es extraño, porque el eterno retorno es la forma extrema de nihilismo y es el más fuerte de los argumentos tradicionalmente utilizados por la tradición pesimista para devaluar la existencia terrena y dirigir la mirada hacia lo suprasensible, lo eterno, lo inmóvil. Piénsese en el «nada hay nuevo bajo el sol» y en el «todo es vanidad» del Eclesiastés $^{40}$. O en el vendedor de calendarios de Leopardi que aceptaría volver a vivir los años pasados solo con la condición de tener una vida distinta ${ }^{41}$. Según Schopenhauer: «Quizás nunca se de el caso de que un hombre al final de su vida, si tiene capacidad de reflexión y es sincero, desee volver a vivirla; por el contrario preferiría elegir no existir", y condensado en una frase resumía así su pesimismo: «Si se abriesen los sepulcros y se preguntase a los muertos si quisieran resucitar, probablemente moverían negativamente la cabeza» ${ }^{42}$. Eduard von Hartmann también consideraba la repetición de lo idéntico como la más fuerte demostración de la doctrina del pesimismo. En un punto clave de su obra, el capítulo titulado «La irracionalidad del querer y la miseria del ser», imaginaba que la muerte pidiera a un burgués satisfecho y afortunado que aceptase volver a vivir de nuevo su existencia.

Imaginemos un hombre de mediana cultura que posea los privilegios de una posición envidiable, plenamente consciente de las ventajas de las que goza, un hombre que se libró de los males y que todavía no está cansado de disfrutar las alegrías de la vida; supongamos que la muerte venga a su encuentro y le hable en estos términos: «Tu vida ha llegado a su fin, ha llegado la hora en que debes convertirte en presa de la nada. Pero depende de ti decidir si quieres volver a empezar otra vez la vida de la misma manera, en las mismas condiciones y con el completo olvido del pasado.

[1995], 61-94, p. 70, nota), la métrica de la ronda de Zaratustra está construida de manera que imite el sonido de las campanas: «Oh Mensch! Gieb Acht! / Was spricht die tiefe Mitternacht? / Ich schlief, ich schlief -, / Aus tiefem Traum bin ich erwacht:-». Por lo demás, en los esbozos preparatorios se dice que Zaratustra "gustaba contar y cantar con rimas los toques de la campana de medianoche» (FP III 695: 31[64]). Es una lástima que Mahler no haya tenido esto en cuenta cuando compuso este fragmento en su tercera sinfonía.

40. «iOh vanidad inmensa: todo es vanidad [...] Lo que ha sido eso será, lo que se ha hecho eso se hará. No hay nada nuevo bajo el sol [...] He observado todas las obras que se han hecho bajo el sol y he concluido que todo es vanidad y ocupación sin sentido» (Qohélet, 1).

41. Véase la opereta moral Dialogo di un venditore d'almanacchi e di un passeggere: «PAss. Non tornereste voi a vivere cotesti vent'anni, e anche tutto il tempo passato, cominciando da che nasceste? VEND. Eh, caro signore, piacesse a Dio che si potesse. PASs. Ma se aveste a rifare la vita che avete fatta né più né meno, con tutti i piaceri e i dispiaceri che avete passati? VEND. Cotesto non vorrei. PASS. Oh che altra vita vorreste rifare? La vita c'ho fatta io, o quella del principe o di chi altro? O non credete che io, e che il principe, e che chiunque altro, risponderebbe come voi per l'appunto; e che avendo a rifare la stessa vita che avesse fatta, nessuno vorrebbe tornare indietro? VEND. Lo credo cotesto. PASS. Né anche voi tornereste indietro con questo patto, non potendo in altro modo? VEND. Signor no davvero, non tornerei» (G. Leopardi, Operette morali, Torino: Loescher, 1993). Pasando del pesimismo del siglo XVIII a la literatura de la décadence, encontramos el Journal des Goncourt: "No hay hombre que quiera volver a vivir su vida. A duras penas se encuentra a una mujer que quiera volver a vivir sus dieciocho años. Esto es lo que considera la existencia» (E. y J. H. de Goncourt, Journal des Goncourt. Mémoires de la vie littéraire, Paris: Charpentier, 1887, p. 193). El ejemplar que tenía Nietzsche, en el que este pasaje está subrayado, se conserva en la Herzogin Anna Amalia Bibliothek de Weimar, en el lugar C 550-a.

42. A. Schopenhauer, El mundo como voluntad y representación, cit., vol. I, $\$ 59$, y vol. II, cap. XLI, p. 515. 
¡Elige!». Dudo que este hombre prefiera comenzar de nuevo el juego de la vida más bien que entrar en la nada ${ }^{43}$.

Nietzsche, por su parte, había tomado esta imagen en el primer anuncio público de la doctrina del eterno retorno, el célebre aforismo 341 de la Gaya ciencia. En este aforismo es un demon el que deslizándose un día en la más solitaria de sus soledades, pide al hombre que si quiere revivir una vida idéntica a la que ha vivido. Según la Gaya ciencia, frente a este anuncio son posibles dos actitudes. La respuesta común es el rechazo desesperado: «¿No te echarías al suelo, rechinarías los dientes y maldecirías al demon que te hablase así?». Pero Nietzsche introduce también la posibilidad de una aceptación del retorno: «O has vivido alguna vez un instante inmenso, en el que esta hubiera sido la respuesta: 'iTu eres un dios y nunca oí nada más divino!'?». La Gaya ciencia nos dice realmente esto: que Nietzsche ha entrevisto la posibilidad de una respuesta afirmativa a la pregunta del demon. En la Segunda canción de danza, Nietzsche juega a hacer la parodia de Schopenhauer, de Hartmann y de sí mismo; porque esta vez no es la muerte o un demon los que agitan el eterno retorno como una pesadilla delante de un hombre satisfecho de su vida, sino al contrario, es Zaratustra, desesperado y al borde del suicidio, el que anuncia a la vida la doctrina del retorno. Y ¿qué es lo que ha susurrado Zaratustra al oído de la vida, en medio de sus cabellos revueltos y alocados mechones amarillos? Ciertamente no le ha dado una disertación sobre las leyes de la termodinámica y las antinomias cosmológicas, sobre los argumentos que demuestran la plausibilidad filosófica y científica de la hipótesis del eterno retorno. Por lo demás, estos argumentos eran conocidos por la cultura europea de la época: el eterno retorno era una de las teorías que animaban el debate científico y, por ejemplo, Ludwig Boltzmann, completamente independiente de Nietzsche, la expondrá al final de sus célebres lecciones sobre la teoría cinética de los gases ${ }^{44}$. No es esto lo que ha descubierto Zaratustra. Zaratustra susurra a la vida el sentido nuevo que tiene para él el eterno retorno. Confía en la vida que ha vivido un instante inmenso y que por amor al instante todas las cosas humanas tienen ahora para él un inmenso valor, porque todos los otros acontecimientos están encadenados a aquel instante y necesariamente retornarán con él.

Esta interpretación se confirma en el penúltimo capítulo del cuarto Zaratustra, La canción del noctámbulo — similar a la Segunda canción de danza que es el penúltimo de la tercera parte-, en el que vuelve a sonar la campana de medianoche. Después de la fiesta del asno, el hombre más feo toma la palabra. El hombre más feo, uno de los hombres superiores al que se dedica la cuarta parte del Zaratustra, es la personificación del sentido histórico, conoce el carácter horrible de la historia de la humanidad y es consciente de lo difícil que es soportar la repetición de este conjunto insensato de masacres realizadas y de esperanzas rotas ${ }^{45}$. Cuanto

43. E. von Hartmann, Philosophie des Unbewussten. Versuch einer Weltanschauung, Berlin: Carl Duncker, 1869, vol. II, cap. 12, p. 534.

44. Cf. P. D'Iorio, «L'annuncio dell'eterno ritorno in Così parlò Zarathustra»: Cultura tedesca. Nietzsche 20 (2002), ed. S. Barbera, 85-97, y La linea e il circolo. Cosmologia e filosofia dell'eterno ritorno in Nietzsche, Genova: Pantograf, 1995, pp. 362 ss.

45. El hecho de que el hombre más feo represente el sentido histórico (y el asesino de Dios) es corroborado por los manuscritos preparatorios: véanse los fragmentos FP III 25[101], 31[10] y 32[4]. 
más se acentúa el sentido histórico, más difícil es aceptar el eterno retorno; y sin embargo el hombre más feo dice:

Gracias a este día - yo estoy por primera vez contento de haber vivido mi vida entera.

Y no me basta con atestiguar esto. Merece la pena vivir en la tierra: un solo día, una sola fiesta con Zaratustra me ha enseñado a amar la tierra.

«¿Esto era — la vida?», quiero decirle yo a la muerte. «iBien! iOtra vez!».

Justo en aquel momento la vieja campana comienza a toca la medianoche y Zaratustra comienza a cantar su ronda comentando cada verso. En el décimo de los doce parágrafos de este capítulo, se explica el razonamiento anticipado del hombre más feo que toma y transforma el sentido faustiano del instante. Escribía Goethe:

\author{
Si dijese al instante: \\ ipárate!iEres bello \\ Entonces podrás ponerme cadenas, \\ entonces moriré a gusto \\ entonces podrá tocar la campana a muerto ${ }^{46}$.
}

Naturalmente, en la cita de Goethe viene evocada también una Totenglocke, una campana que toca a muerto. Zaratustra responde así a Fausto en el décimo parágrafo de este capítulo.

¿Habéis dicho sí alguna vez a un solo placer? Oh amigos míos, entonces dijisteis sí a todo dolor. Todas las cosas están encadenadas, trabadas, enamoradas, -

- ¿̇habéis querido en alguna ocasión una sola ve vez, habéis dicho en alguna ocasión «itú me agradas felicidad! iDardo! iInstante! iEntonces quisisteis que todo vuelva!

- todo de nuevo, todo eterno, todo encadenado, trabado, enamorado, oh, entonces amasteis el mundo, -

- vosotros eternos, amadlo eternamente y para siempre: y también al dolor indecible: ipasa, pero vuelve! Pues todo placer quiere — ieternidad!»

El eterno retorno es la antítesis más radical de toda teleología filosófica o científica y de la temporalidad lineal de la tradición cristiana: en el cosmos del eterno retorno no hay ya espacio para la creación, providencia y redención. Ya no es posible orientar o cerrar el tiempo: cada instante huye, pero está destinado a volver, idéntico - a nuestra alegría o condenación. Pero entonces, équién podría desear revivir la misma vida otra vez? ¿Quién podría regocijarse al quitar la flecha de las manos del dios Cronos para poner el anillo en el dedo de la eternidad? Goethe buscaba un instante en el que poder decir: «Párate, eres bello». Nietzsche está a la espera de un hombre que pueda decir en cada instante: «Pasa, pero vuelve idéntico, por toda la eternidad».

Aquí se unen las dos campanas: la negra campana de la medianoche y la campana azul del mediodía. Y de hecho Nietzsche escribe todavía en el décimo parágrafo de este capítulo, poco antes de las palabras citadas: «Precisamente ahora mi mundo llega a ser perfecto. Medianoche es también mediodía». El eterno retorno une el mundo perfecto y lleno de felicidad del mediodía, y su tran-

46. J. W. v. Goethe, Faust, vv. 1698 ss. 
quilizadora campana de la inmanencia, al nihilismo de la medianoche: si habéis dicho sí también a un solo instante de placer, entonces habéis dicho si también a la campana de medianoche y a todo su dolor. El día es más fuerte que la noche, la afirmación más que la negación, el placer más que el dolor ${ }^{47}$. Por eso, la frase «el mundo es más profundo que cuanto piensa el día» resuena una primera vez, cuando Zaratustra habla de la campana azul en el capítulo Antes de que el sol salga, y se repite luego en la ronda de la campana de medianoche.

\section{EPÍLOGO DE LA CAMPANA}

Pero la historia no termina aquí: hay un epílogo, un epílogo a la campana. En 1885 Nietzsche proyecta una nueva edición y corrección de Humano, demasiado humano dentro de sus obras completas. El proyecto no se llevará a cabo, pero en los cuadernos se conservan algunas huellas de este trabajo. En uno de estos apuntes, el filósofo recorre los temas principales de Humano, demasiado humano y concluye con la siguiente exclamación: «IV Conclusión: en Génova: Oh amigos míos, ¿̇comprendéis vosotros este 'a pesar de'?» ${ }^{48}$.

Por lo tanto era perfectamente consciente de que el aforismo 628 es la verdadera conclusión del libro. En este artículo hemos tratado de comprender qué significa este trotzdem y qué reflexión podrían suscitar los guiones largos de suspensión. Siguiendo atentamente las estratificaciones de sentido contenidas en las imágenes de las campanas de Génova nos hemos sorprendido de la riqueza de referencias intertextuales, de la coherencia de referencias intratextuales, de la fuerza estructurante de los efectos de eco creados por la posición de ninguna manera casual de los textos en la arquitectura de la obra. Este libro entero rezuma actualidad, que marca la separación del movimiento wagneriano, que discute los principales temas en la moda de la filosofía positivista y pesimista de la época, lleva en el título una referencia oculta a Platón que nos lleva al aforismo sobre las campanas de Génova, el cual a su vez nos reenvía al topos literario de la desvalorización de la existencia y también a una dolorosa reminiscencia biográfica. La fascinación de la filosofía de Nietzsche y de su lenguaje no provienen probablemente ni de su actualidad ni de su inactualidad, sino de la unión de ambas y del continuo cambio de perspectiva, de enfoque, desde lo más cercano a lo más lejano, de lo particular a lo general. En definitiva, hemos encontrado confirmación de la posición particular de la reflexión sobre el valor de las cosas humanas en el pensamiento de Nietzsche. Si en El nacimiento de la tragedia las cosas humanas tenían valor solo en relación a la metafísica del

47. Entre otras referencias presentes en este texto, recordemos que Nietzsche invierte la antítesis entre el día y la noche contenida en el Tristán e Isolda de Wagner. La conciliación con el todo no acontece en una dimensión metafísica nocturna a través de la pasión amorosa que empuja a la pérdida de la individualidad como en Tristán (y como en El nacimiento de la tragedia), sino en la aceptación de la inmanencia. Sobre la filosofía del Tristán y sus derivaciones, contaminaciones y distorsiones feuerbachianas y schopenhauerianas, cf. S. Barbera, La comunicazione perfetta. Wagner tra Feuerbach e Schopenhauer, Pisa, 1984, pp. 87 ss.

48. «IV Schluß: In Genua: Oh meine Freunde. versteht ihr dieß 'Trotzdem'? — — , FP III 883: 42[3]. 
arte, cuando Nietzsche ya no cree más en la metafísica debe decir con Platón, o mejor, con Leopardi, que ninguna de las cosas humanas es digna de valor. Pero luego la inclusión de un trotzdem abre un arco de posibilidades dentro de un escepticismo resignado pero activo, que se interesa por las cosas próximas y sostiene, con Epicuro, que algunas cosas humanas tienen valor. Ya que, gracias al pensamiento del eterno retorno de lo mismo, para el filósofo todas las cosas humanas adquirirán un inmenso valor. 